\title{
Prophylactic antiviral therapy in low-risk patients infected with the hepatitis B virus with solid tumors
}

\author{
Qiong Qin ${ }^{1}$, Xin Wang', Ai-Ping Zhou ${ }^{2}$, Lin Yang ${ }^{2}$, Jin-Wan Wang², Dian-Sheng Zhong ${ }^{1}$
}

\author{
${ }^{1}$ Department of Medical Oncology, Tianjin Medical University General Hospital, \\ Tianjin Medical University, China \\ 2Department of Medical Oncology, Cancer Hospital Chinese Academy of Medical Sciences, \\ Peking Union Medical College, China
}

Submitted: 7 October 2020; Accepted: 28 December 2020

Online publication: 24 March 2021

Arch Med Sci

DOI: https://doi.org/10.5114/aoms/117703

Copyright @ 2021 Termedia \& Banach

\begin{abstract}
Introduction: This study aimed to evaluate the prophylactic antiviral therapy in low-risk patients with hepatitis B virus (HBV) infections during chemotherapy.

Material and methods: From January 2011 to March 2018, HBsAg-positive patients were analyzed in this retrospective study. The HBV reactivation, related hepatitis, chemotherapy delay, and fulminant hepatic failure in lowrisk patients between the prophylactic anti-HBV therapy (prophylaxis group) and the non-prophylactic anti-HBV therapy group (control group) were compared.

Results: There were 68 patients in the prophylaxis group and 102 patients in the control group. The results showed that the HBV reactivation was not significantly different between the prophylaxis group and the control group $(p=0.741)$. Three and 5 patients with HBV-related hepatitis were detected in the prophylaxis and control groups, respectively. Moreover, 2 and 4 patients with HBV activation-related chemotherapy delay were detected in the two groups, respectively, without any significant difference $(p>0.05)$. Multivariate analysis showed that HBV DNA titer was associated with HBV reactivation in low-risk patients $(p=0.001)$.

Conclusions: Prophylactic antiviral therapy might not reduce the HBV reactivation of low-risk solid malignancies (non-HCC, non-hematological lymphatic cancer, and HBV DNA titer < $100 \mathrm{IU} / \mathrm{ml}$ ). For low-risk patients, monitoring the HBV DNA titers and liver function tests in the follow-up observations might be an optimal and cost-effective strategy.
\end{abstract}

Key words: solid malignancies, chemotherapy, HBV reactivation, prophylactic antiviral therapy, tumor.

\section{Introduction}

Currently, approximately $30 \%$ of the worldwide population is infected or has been infected with the hepatitis B virus (HBV) [1] and approximately 350-400 million individuals in the world are HBV carriers [2]. In recent years, the incidence of malignancies has increased every year. In 2012, there were 14.1 million cases of new-onset malignancies worldwide, and it is estimated that there will be more than 18 million cases recorded by the end of 2018 [3, 4]. Therefore, a large number of hepatitis B patients with malignancies will be noted. Systemic cytotoxic chemotherapy is one of the crucial methods for the treatment of malignancies.

\author{
Corresponding author: \\ Dian-Sheng Zhong \\ Department of Medical \\ Oncology \\ Tianjin Medical University \\ General Hospital \\ Tianjin Medical University \\ China \\ E-mail: dzhong@tmu.edu.cn
}


During and after chemotherapy, it might disrupt the immune balance of the body and lead to HBV reactivation [5-7]. Clinical manifestations, from the mild elevation of alanine transaminase (ALT) to the deterioration of liver function, liver failure, and death due to chemotherapy delay, might occur after HBV reactivation [8], which in turn would affect the efficacy of systemic anti-cancer therapy. The guidelines, therefore, recommend prophylactic antiviral therapy for 6-12 months in HBsAg-positive patients with malignancies before chemotherapy $[9,10]$.

However, there is a lack of clinical research on the need for prophylactic anti-HBV therapy in lowrisk patients undergoing cytotoxic chemotherapy (hepatitis B patients with non-hematological lymphatic cancer, non-HCC, and low HBV DNA titers). Thus, this retrospective study aimed to evaluate the prophylactic antiviral therapy in those low-risk patients with HBV-infections during chemotherapy.

\section{Material and methods}

\section{Patients}

From January 2011 to July 2013, HBsAg-positive patients with solid tumors who received chemotherapy in the Cancer Hospital of the Chinese Academy of Medical Sciences and the Tianjin Medical University General Hospital were enrolled in this study. The Ethics Committees of our hospital approved this retrospective study.

\section{Inclusion and exclusion criteria}

Inclusion criteria: (1) patients with malignancies that were pathologically confirmed; (2) patients aged $\geq 18$ years; and (3) patients who were HBsAg positive; (4) HBV DNA titers < $100 \mathrm{lU} / \mathrm{ml}$. Exclusion criteria: (1) patients with HCC, hematological malignancies, and lymphoma; (2) patients who had anti-hepatitis $C$ virus antibodies or consumed alcohol excessively (> $20 \mathrm{~g} /$ day); (3) patients with acute fulminant hepatitis; and (4) HBV DNA titer was not detected before chemotherapy or $\mathrm{HBeAg}$-positive patients.

\section{Study design and measurements}

The patients were divided into the prophylaxis group (prophylactic therapy received before chemotherapy) and the control group (anti-HBV therapy received after HBV reactivation). In the prophylaxis group, the patients were administered anti-HBV drugs orally 1 week before chemotherapy until at least 3 months after the end of chemotherapy: lamivudine $100 \mathrm{mg} /$ day (GKS), entecavir $0.5 \mathrm{mg} /$ day (Bristol-Myers Squibb and Chia Tai Tianqing), and adefovir dipivoxil $10 \mathrm{mg} /$ day (GKS). Parameters such as HBV reactivation risk, related hepatitis, chemotherapy delay, and severe liver failure caused by hepatitis $B$ reactivation were compared between the two groups.

In the hepatitis B screening, $\mathrm{HBeAg}$ and $\mathrm{HBe}$ $A b$ were detected with a radioimmunoassay kit (radioimmunoassay (RIA) enzyme-linked immunosorbent assay (ELISA) rapid kit; Abbott Laboratories, North Chicago, IL, USA) and HBsAg and HBsAb were detected with an Abbott HBsAg analyzer and the sensitivity was $0.05 \mathrm{IU} / \mathrm{ml}$. The lower limit of detection for HBV DNA by the Roche Molecular System (Cobas Amplicor HBV monitor test; Roche Molecular Systems, Pleasanton, CA) was $20 \mathrm{lU} / \mathrm{ml}$.

\section{Definition of hepatic events}

HBV reactivation is defined as follows: (i) $a \geq 2$ log (100-fold) increase in HBV DNA compared to the baseline level and (ii) an HBV DNA $\geq 3 \log$ $(1,000) \mathrm{IU} / \mathrm{ml}$ in a patient with a previously undetectable level in the serum during the follow-up period [10]. HBV-related hepatitis: the serum ALT level (the normal upper limit is 40 IU/I) more than 3-fold and >100 U/I after HBV reactivation. The chemotherapy delay is defined as more than 8 days of chemotherapy. The abnormal liver function is defined as ALT or AST > $40 \mathrm{U} / \mathrm{l}$ in the liver function tests.

\section{Observational index}

The observational index included serum $\mathrm{HBeAg}$, anti-HBeAb, and HBV DNA concentrations and biochemical parameters, such as serum bilirubin, AST, and ALT levels before each chemotherapy session. The patients were followed up every 3-6 months until death.

\section{Statistical analysis}

We used the software program SPSS 17.0 (IBM, Chicago, USA) to conduct the statistical analysis. Discontinuous variables were expressed as a percentage (\%). Continuous variables were expressed as mean $\pm \mathrm{SD}$. In this study, a $t$-test was used for two-group comparisons of a normal distribution. The non-normally distributed continuous data were compared using non-parametric tests. The counting data were tested by a $\chi^{2}$ test. We used a stepwise forward method and the logistic model was used in the multivariable analysis of the competing risks. $P<0.05$ was considered statistically significant.

\section{Results}

\section{General characteristics}

A total of 260 participants were included in this study. Also, 90 patients were excluded due to the following reasons: 42 patients had HBV 
Table I. Baseline characteristics of patients with HBsAg-positive solid tumor

\begin{tabular}{|c|c|c|c|}
\hline Variables & Prophylaxis group, $n=68(\%)$ & Control group, $n=102(\%)$ & $P$-value \\
\hline Age [years]; mean; SD & $52.6 ; 10.4$ & $52.5 ; 10.7$ & 0.958 \\
\hline \multicolumn{4}{|l|}{ Gender, $n(\%)$} \\
\hline Male & $35(51.5)$ & $51(50)$ & \multirow[t]{2}{*}{0.851} \\
\hline Female & $33(48.5)$ & $51(50)$ & \\
\hline \multicolumn{4}{|l|}{ Tumor type, $n(\%)$} \\
\hline Breast cancers & $16(23.5)$ & $19(18.6)$ & \multirow[t]{4}{*}{0.584} \\
\hline Lung cancers & $22(32.4)$ & $28(27.5)$ & \\
\hline Gastrointestinal cancers & $26(38.2)$ & $50(49.0)$ & \\
\hline Other cancers & $4(5.9)$ & $5(4.9)$ & \\
\hline \multicolumn{4}{|l|}{ Tumor stage, $n(\%)$} \\
\hline Stage I-III & $32(47.1)$ & $51(50.0)$ & \multirow[t]{2}{*}{0.755} \\
\hline Stage IV & $36(52.9)$ & $51(50.0)$ & \\
\hline \multicolumn{4}{|l|}{ Adjuvant chemotherapy, $n$ (\%) } \\
\hline Yes & $34(50.0)$ & $49(48.0)$ & \multirow[t]{2}{*}{0.802} \\
\hline No & $34(50.0)$ & $53(52.0)$ & \\
\hline \multicolumn{4}{|l|}{ HBsAg level [IU/ml], $n(\%)$} \\
\hline$\geq 250$ & $6(8.8)$ & $3(2.9)$ & \multirow[t]{2}{*}{0.159} \\
\hline$<250$ & $62(91.2)$ & $99(97.1)$ & \\
\hline \multicolumn{4}{|l|}{ HBV DNA status, $n(\%)$} \\
\hline Positive & $15(22.1)$ & $12(11.8)$ & \multirow[t]{2}{*}{0.072} \\
\hline Negative & $53(77.9)$ & $90(88.2)$ & \\
\hline \multicolumn{4}{|l|}{ Baseline ALT [U/I] } \\
\hline Mean & 22.1 & 23.9 & \multirow[t]{2}{*}{0.437} \\
\hline SD & 12.1 & 15.6 & \\
\hline \multicolumn{4}{|l|}{ Baseline liver metastasis, $n(\%)$} \\
\hline Yes & $23(33.8)$ & $48(47.1)$ & \multirow[t]{2}{*}{0.086} \\
\hline No & $45(66.2)$ & $54(52.9)$ & \\
\hline \multicolumn{4}{|l|}{ Chemotherapy regime, $n$ (\%) } \\
\hline Anthracycline-based & $2(6.9)$ & $4(3.9)$ & \multirow[t]{5}{*}{0.683} \\
\hline Fluorouracil-based & $24(35.3)$ & $40(39.2)$ & \\
\hline Taxane-based & $10(14.7)$ & $21(20.6)$ & \\
\hline Anthracycline + taxane & $12(17.6)$ & $15(14.7)$ & \\
\hline Other & $20(29.4)$ & $22(21.6)$ & \\
\hline \multicolumn{4}{|l|}{ Cycles of chemotherapy } \\
\hline Mean & 6.5 & 6.5 & \multirow[t]{2}{*}{0.950} \\
\hline SD & 2.8 & 2.7 & \\
\hline \multicolumn{4}{|l|}{ Duration of follow-up (months) } \\
\hline Mean & 38.7 & 36.9 & \multirow[t]{2}{*}{0.657} \\
\hline SD & 23.7 & 23.9 & \\
\hline
\end{tabular}

$H B S A g$ - hepatitis B surface antigen, ALT - alanine transaminase. 


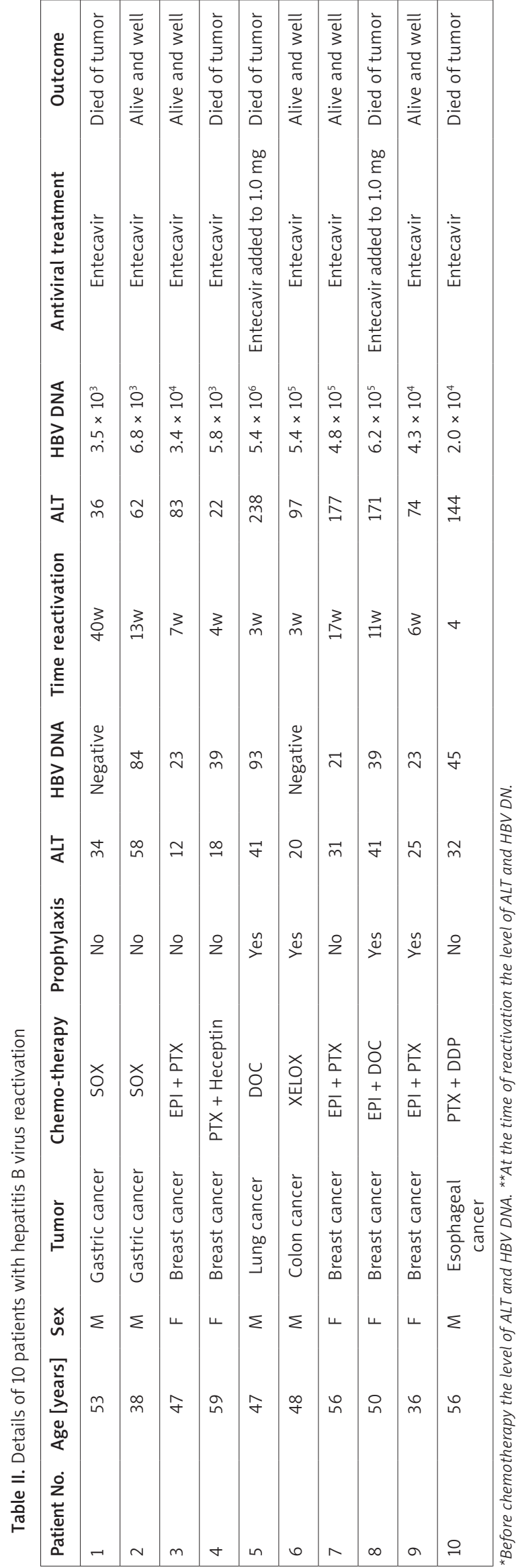

DNA > $100 \mathrm{U} / \mathrm{ml}$ at the baseline; 44 patients had a lymphoma; in 4 patients HBV DNA was not detected at baseline. The follow-up ranged from 7.0 to 80.0 months, the final follow-up was in September 2018, and the median duration was 30 months. 143 patients were negative for HBV DNA and 27 patients had HBV DNA titer > $20 \mathrm{IU} / \mathrm{ml}$, ranging from 21 to $93 \mathrm{IU} / \mathrm{ml}$, with a median of $36 \mathrm{IU} / \mathrm{ml}$. Nine patients with HBsAg were above the detection limit of $250 \mathrm{lU} / \mathrm{ml}$ and 161 patients had an HBsAg quantification of $0.01-240 \mathrm{IU} / \mathrm{ml}$. The cohort consisted of 35 breast cancer, 50 lung cancer, 76 gastrointestinal cancer, 2 ovarian cancer, 2 nasopharyngeal carcinomas, 1 synovial sarcoma, 1 urothelial bladder carcinoma, 1 prostatic cancer, 1 testicular seminoma, and 1 parotid carcinoma patients. Eighty-seven patients included in this study had palliative chemotherapy and 83 patients had postoperative adjuvant therapy.

Sixty-eight of the 170 patients received prophylactic anti-HBV therapy (prophylaxis group), while there were 102 patients without prophylactic antiHBV treatment (control group). Age, gender, cancer type, tumor stage, initial treatment plan, and treatment cycle of the patients were similar between the two groups (Table I).

\section{HBV reactivation, HBV-related hepatitis, and chemotherapy delay}

The results showed that the cumulative HBV reactivation rates were $2.0 \%, 5.9 \%$, and $6.7 \%$ in the control group and $2.9 \%, 4.4 \%$, and $4.4 \%$ in the prophylaxis group at 10,30, and 60 weeks after the start of chemotherapy, respectively (Figure $1 ; p=0.515$ ).

The HBV reactivation had no significant difference between the two groups ( $p=0.741$, Figure 2 ). The cases of hepatitis $B$ reactivation is described in detail in Table II. The prevention of HBV reactivation was similar among the three antiviral drugs $p=0.373)$. HBV reactivation also occurred in 9 patients during chemotherapy. HBV reactivation occurred in 1 patient at 12 weeks after chemotherapy (control group). Furthermore, 23 (33.8\%) and 40 patients (39.2\%) experienced abnormal liver function in the two groups ( $p=0.515$ ). Of these 63 patients with abnormal liver function, $8(12.7 \%)$ were associated with HBV reactivation, 46 (73.0\%) with chemotherapy-induced liver injury, and 9 with tumor progression (14.3\%). A further analysis revealed 8 cases of HBV activation-related hepatitis, including 3 cases in the prophylaxis group and 5 cases in the control group; the incidence of both groups was also similar ( $4.4 \%$ vs. $4.9 \%$, $p=0.882$, Figure 3 ). There were also, interestingly, 13 and 25 cases of chemotherapy delay in the two groups $(p=0.456)$. The correlation between chemotherapy delay and HBV reactivation was $2.9 \%$ 


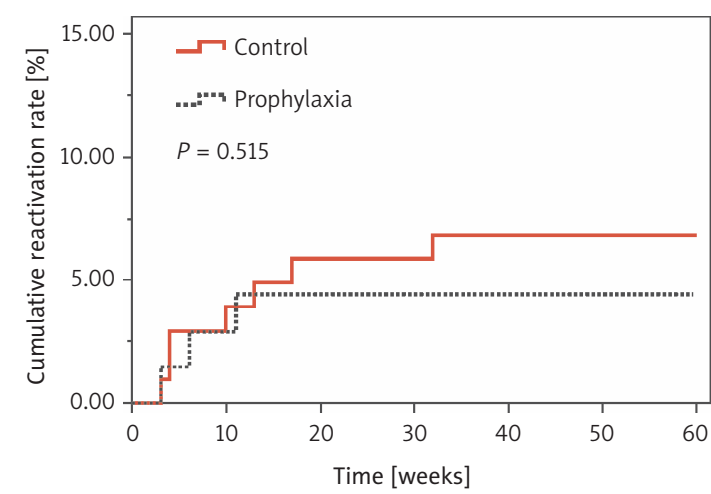

Figure 1. Cumulative reactivation rate in the prophylaxis and control groups

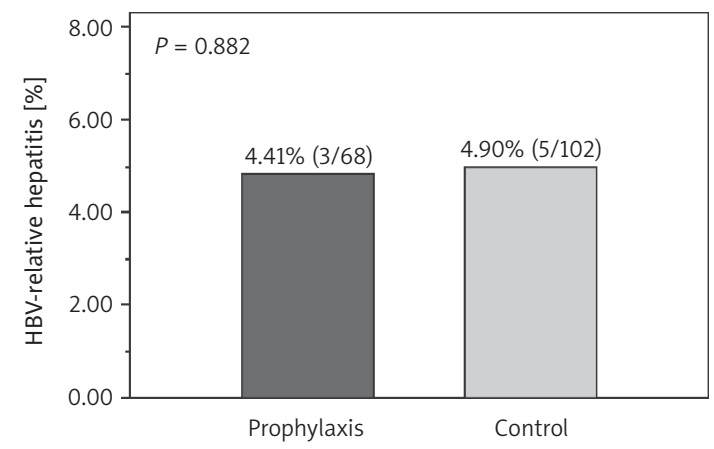

Figure 3. Hepatitis B virus (HBV)-related hepatitis in the prophylaxis and control groups

$(2 / 68)$ and $3.9 \%(4 / 102)$, respectively, without any significant difference ( $p=0.875$, Figure 4$)$.

\section{Risk factor}

Age, gender, tumor type, adjuvant therapy, combination with liver metastasis, HBsAg level, HBV DNA titer, steroid-containing regimen, taxanebased regimen, anthracycline-based regimen, fluorouracil-based regimen, prophylactic anti-HBV therapy, and whether ALT was elevated before chemotherapy were analyzed. The results showed that the taxane-based chemotherapy regimen and HBV DNA titer were associated with HBV reactivation (11.3\% vs. $2.8 \%, p=0.038 ; 29.6 \%$ vs. $1.4 \%$, $p<0.001)$ (Table III). The above factors $(p<0.2)$ were also analyzed by multivariate analysis and the results confirmed that HBV DNA titer was an independent risk factor for HBV reactivation in low-risk patients ( $\mathrm{HR}=20.807,95 \% \mathrm{Cl}$ : 3.644118.817, $p<0.05$ ) (Table IV).

\section{Discussion}

Recently, approximately $51.7-72.0 \%$ of patients with hematological malignancies and lymphomas developed $\mathrm{HBV}$ reactivation if the prophylactic antiHBV therapy was not administered [11-15]. Prophylactic antiviral therapy is also still required for patients who have been previously infected with

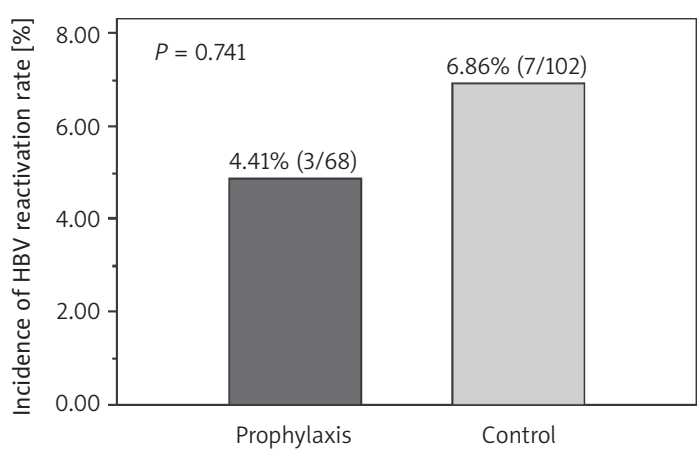

Figure 2. Hepatitis B virus (HBV) reactivation in the prophylaxis and control groups

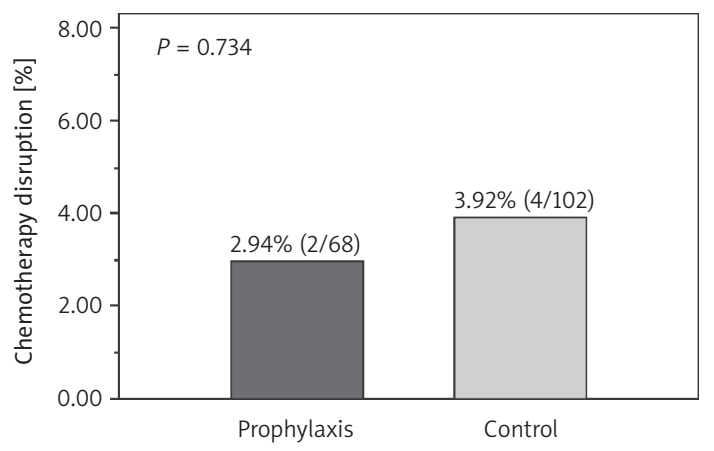

Figure 4. Hepatitis B virus (HBV)-related chemotherapy disruption in the prophylaxis and control groups

HBV while undergoing autologous and allogeneic hematopoietic stem cell transplantation and received rituximab combined with chemotherapy. Also, approximately $13.0-43.0 \%$ of these patients had HBV reactivation during and after chemotherapy $[11,16]$. The occurrence of tumors has also recently increased [17-19]. Chemotherapy-induced HBV reactivation was an independent risk factor in hepatitis B patients with solid tumors [20]. Previous studies on solid tumors including patients with hepatocellular carcinoma (HCC) showed that the HBV reactivation risk was significantly higher than that in other solid tumors [21]. Anti-HBV therapy significantly improved the prognosis of patients with hepatitis and HCC [22].

This study showed that prophylactic anti-HBV therapy could not reduce the HBV reactivation in hepatitis B patients with low-risk solid malignancies (non-hematological lymphatic cancer, nonHCC, HBV DNA titer < $100 \mathrm{IU} / \mathrm{ml}$ ). It was previously reported that the higher the score was, the higher was the risk of HBV reactivation [18]. All patients in the current study were low-risk patients and the overall HBV reactivation risk was $5.9 \%$, which was similar to the above study [19, 23-25].

Recent studies have also reported that the HBV reactivation risk in solid malignancies treated with lamivudine for prophylactic anti-HBV therapy was $0-7 \%[19,24,25]$. Thus, the HBV reactivation 
Table III. Analysis of potential risk factors of HBV reactivation

\begin{tabular}{|c|c|c|c|}
\hline Characteristics & $\begin{array}{l}\text { Patients with HBV reactivation, } \\
\qquad n=10(\%)\end{array}$ & $\begin{array}{l}\text { Patients without } \mathrm{HBV} \text { reactivation, } \\
\qquad n=160(\%)\end{array}$ & $P$-value \\
\hline \multicolumn{4}{|l|}{ Age [years], $n(\%)$} \\
\hline$\leq 65$ & $7(70.0)$ & $91(56.9)$ & \multirow[t]{2}{*}{1.000} \\
\hline$>65$ & $3(30.0)$ & $69(43.1)$ & \\
\hline \multicolumn{4}{|l|}{ Gender, $n(\%)$} \\
\hline Male & $5(50.0)$ & $81(50.6)$ & \multirow[t]{2}{*}{1.000} \\
\hline Female & $50(50.0)$ & 79 (49.4) & \\
\hline \multicolumn{4}{|l|}{ Tumor type, $n$ (\%) } \\
\hline Gastrointestinal cancers & $4(40.0)$ & $72(45.0)$ & \multirow[t]{2}{*}{0.758} \\
\hline Other cancers & $6(60.0)$ & $88(55.0)$ & \\
\hline \multicolumn{4}{|l|}{ Live metastasis, $n(\%)$} \\
\hline Yes & $4(40.0)$ & $67(41.9)$ & \multirow[t]{2}{*}{0.907} \\
\hline No & $6(60.0)$ & $93(58.1)$ & \\
\hline \multicolumn{4}{|l|}{ Adjuvant chemotherapy, $n$ (\%) } \\
\hline Yes & $6(60.0)$ & $78(48.8)$ & \multirow[t]{2}{*}{0.490} \\
\hline No & $4(40.0)$ & $82(51.2)$ & \\
\hline \multicolumn{4}{|l|}{ HBsAg level [IU/ml], $n$ (\%) } \\
\hline$\geq 250$ & $2(20.0)$ & $7(4.4)$ & \multirow[t]{2}{*}{0.09} \\
\hline$<250$ & $8(80.0)$ & $153(95.6)$ & \\
\hline \multicolumn{4}{|l|}{ HBV DNA status, $n(\%)$} \\
\hline Positive & $8(80.0)$ & 19 (11.9) & \multirow[t]{2}{*}{$<0.001$} \\
\hline Negative & $2(20.0)$ & $141(88.1)$ & \\
\hline \multicolumn{4}{|l|}{ Baseline ALT [U/I], $n(\%)$} \\
\hline$>40$ & $3(30.0)$ & $20(12.5)$ & \multirow[t]{2}{*}{0.116} \\
\hline$\leq 40$ & $7(70.0)$ & $140(87.5)$ & \\
\hline \multicolumn{4}{|c|}{ Steroid-containing treatment, $n(\%)$} \\
\hline Yes & $7(70.0)$ & $75(46.9)$ & \multirow[t]{2}{*}{0.200} \\
\hline No & $3(30.0)$ & $54(53.1)$ & \\
\hline \multicolumn{4}{|l|}{ Taxane-based, $n(\%)$} \\
\hline Yes & $7(70.0)$ & $55(34.4)$ & \multirow[t]{2}{*}{0.038} \\
\hline No & $3(30.0)$ & $105(65.6)$ & \\
\hline \multicolumn{4}{|l|}{ Anthracycline-based, $n$ (\%) } \\
\hline Yes & $4(40.0)$ & $31(19.4)$ & \multirow[t]{2}{*}{0.125} \\
\hline No & $6(60.0)$ & $129(80.6)$ & \\
\hline \multicolumn{4}{|l|}{ Fluorouracil-based, $n$ (\%) } \\
\hline Yes & $3(30.0)$ & $64(40.0)$ & \multirow[t]{2}{*}{0.742} \\
\hline No & $7(70.0)$ & $86(60.0)$ & \\
\hline \multicolumn{4}{|l|}{ Prophylactic anti-HBV, $n$ (\%) } \\
\hline Yes & $3(30.0)$ & $65(40.6)$ & \multirow[t]{2}{*}{0.741} \\
\hline No & $7(70.0)$ & $95(59.4)$ & \\
\hline
\end{tabular}


Table IV. Multivariate analysis of HBV reactivation

\begin{tabular}{|lcccc|}
\hline Factor & B & HR & $95 \% \mathrm{Cl}$ & $P$-value \\
\hline Taxane-based (Yes/No) & 0.948 & 2.581 & $0.350-19.034$ & 0.352 \\
\hline Anthracycline-based (Yes/No) & 0.604 & 1.830 & $0.298-11.252$ & 0.515 \\
\hline ALT increased baseline (Yes/No) & 0.786 & 2.194 & $0.384-12.529$ & 0.377 \\
\hline HBsAg $(\leq 250 \mathrm{IU} / \mathrm{ml} />250 \mathrm{IU} / \mathrm{ml})$ & -0.894 & 0.409 & $0.037-4.540$ & 0.467 \\
\hline HBV DNA titer $(20-100 \mathrm{U} /<20 \mathrm{U})$ & 3.035 & 20.807 & $3.644-118.817$ & 0.001 \\
\hline
\end{tabular}

risks in the above studies are similar to those in the prophylaxis group. However, the HBV reactivation risk in the control group was significantly lower than in previous studies $[6,19,25,26]$. The HBV reactivation risk in the non-prophylactic anti-HBV therapy group in previous studies was $16-36 \%$, which was higher than the control group. It may be due to the exclusion of patients with hematological lymphatic cancer, high HBV DNA titers, HBeAg-positive, and HCC [19, 20, 26, 27].

Furthermore, three anti-HBV drugs were used in this study: lamivudine, entecavir, and adefovir dipivoxil. Previously, entecavir was superior to lamivudine in preventing HBV reactivation [28-31]. However, no difference was detected among the three drugs in preventing HBV reactivation in our study, which might be due to the limited sample size.

Single-factor and multivariate analysis of HBV reactivation confirmed that HBV DNA titer is an independent risk factor. Previous studies found that $\mathrm{HBV}$ reactivation might be related to HBV DNA titers before chemotherapy [18-20]. In our study, HBV DNA titers were detectable in $15.9 \%$ of the patients. Despite the low titer of HBV DNA, the rate of $\mathrm{HBV}$ reactivation was significantly increased. Therefore, these patients should be treated with prophylactic antiviral therapy as long as the HBV DNA titer test results are positive.

Health economics is becoming an increasingly critical factor in medical decision-making [32, 33]. The current study confirmed that prophylactic antiviral therapy cannot reduce the rate of HBV reactivation in low-risk patients and that antiviral therapy after HBV reactivation has similar prophylactic effects on chemotherapy delay, hepatitis, and fulminant liver failure. Therefore, from the perspective of cost-efficiency, only follow-ups without prophylactic anti-HBV therapy in low-risk patients can greatly reduce the economic cost of treatment and save medical resources, thereby benefitting both the society and patients.

Limitations: Firstly, the sample size was limited; further randomized controlled trials (RCTs) with larger sample sizes are essential for the substantiation of these findings. Secondly, the participants were Chinese, which might not be optimal for populations in other countries. Thirdly, the covalently closed circular DNA (cccDNA) of HBV is considered to be related to HBV reactivation [34]. However, relevant tests were not carried out in the present study, thereby excluding some highrisk groups of HBV reactivation. Therefore, it is necessary to design a rigorous prospective RCT to verify the above conclusions.

In conclusion, prophylactic nucleoside analog (anti-HBV) therapy during chemotherapy might not reduce $\mathrm{HBV}$ reactivation risk in hepatitis $B$ patients with low-risk solid malignancies (nonhematological lymphatic cancer, non-HCC, and low HBV DNA titers). Therefore, from the perspective of cost-efficiency, the reexamination of HBV DNA titer and liver function is recommended. AntiHBV therapy, especially HBV DNA titer negative, is administered after $\mathrm{HBV}$ reactivation occurs.

\section{Acknowledgements}

We are particularly grateful to all the people who have helped with our article.

\section{Conflict of interest}

The authors declare no conflict of interest.

\section{References}

1. Al-Anazi MR, Nazir N, Abdo AA, et al. Genetic variations of NOD2 and MD2 genes in hepatitis B virus infection. Saudi J Biol Sci 2019; 26: 270-80.

2. Dienstag JL. Hepatitis B virus infection. N Engl J Med 2008; 359: 1486-500.

3. Bray F, Ferlay J, Soerjomataram I, Siegel RL, Torre LA, Jemal A. Global cancer statistics 2018: GLOBOCAN estimates of incidence and mortality worldwide for 36 cancers in 185 countries. CA Cancer J Clin 2018; 68: 394-424.

4. Torre LA, Bray F, Siegel RL, Ferlay J, Lortet-Tieulent J, Jemal A. Global cancer statistics, 2012. CA Cancer J Clin 2015; 65: 87-108.

5. Chen CY, Tien FM, Cheng A, et al. Hepatitis B reactivation among 1962 patients with hematological malignancy in Taiwan. BMC Gastroenterol 2018; 18: 6.

6. Yeo W, Lam KC, Zee B, et al. Hepatitis B reactivation in patients with hepatocellular carcinoma undergoing systemic chemotherapy. Ann Oncol 2004; 15: 1661-6.

7. Gui HL, Xie Q. Diagnosis, management and prevention of hepatitis B virus reactivation during anticancer therapy. Zhonghua Gan Zang Bing Za Zhi 2007; 15: 78-80. 
8. Lau GK. Hepatitis B reactivation after chemotherapy: two decades of clinical research. Hepatol Int 2008; 2: 152-62.

9. European Association for the Study of the Liver. EASL 2017 Clinical Practice Guidelines on the management of hepatitis B virus infection. J Hepatol 2017; 67: 370-98.

10. Terrault NA, Lok ASF, McMahon BJ, et al. Update on prevention, diagnosis, and treatment of chronic hepatitis $B$ : AASLD 2018 hepatitis B guidance. Clin Liver Dis (Hoboken) 2018; 12: 33-4.

11. Bae SK, Gushima T, Saito N, et al. HBV reactivation after hematopoietic stem cell transplantation and rituximabcontaining chemotherapy: a 12-year experience at a single center. Bone Marrow Transplant 2019; 54: 629-31.

12. Yeo W, Chan PK, Ho WM, et al. Lamivudine for the prevention of hepatitis $B$ virus reactivation in hepatitis B s-antigen seropositive cancer patients undergoing cytotoxic chemotherapy. J Clin Oncol 2004; 22: 927-34.

13. Hsu C, Hsiung CA, Su IJ, et al. A revisit of prophylactic lamivudine for chemotherapy-associated hepatitis $B$ reactivation in non-Hodgkin's lymphoma: a randomized trial. Hepatology 2008; 47: 844-53.

14. Lau GK, Yiu HH, Fong DY, et al. Early is superior to deferred preemptive lamivudine therapy for hepatitis B patients undergoing chemotherapy. Gastroenterology 2003; 125: 1742-9.

15. Li YH, He YF, Jiang WQ, et al. Lamivudine prophylaxis reduces the incidence and severity of hepatitis in hepatitis $B$ virus carriers who receive chemotherapy for lymphoma. Cancer 2006; 106: 1320-5.

16. Huang YH, Hsiao LT, Hong YC, et al. Randomized controlled trial of entecavir prophylaxis for rituximab-associated hepatitis $B$ virus reactivation in patients with lymphoma and resolved hepatitis B. J Clin Oncol 2013; 31: 2765-72.

17. Long HY, Huang QX, Yu YY, et al. Dehydrocostus lactone inhibits in vitro gastrinoma cancer cell growth through apoptosis induction, sub-G1 cell cycle arrest, DNA damage and loss of mitochondrial membrane potential. Arch Med Sci 2019; 15: 765-73.

18. Zhao B, Zhang J, Chen X, et al. Mir-26b inhibits growth and resistance to paclitaxel chemotherapy by silencing the CDC6 gene in gastric cancer. Arch Med Sci 2019; 15: 498-503.

19. Babińska A, Pęksa R, Wiśniewski P, et al. Expression of adiponectin receptors 1 and 2 and the leptin receptor in human adrenal tumors. Arch Med Sci 2019; 15: 1254-60.

20. Yeo W, Zee B, Zhong S, et al. Comprehensive analysis of risk factors associating with hepatitis B virus (HBV) reactivation in cancer patients undergoing cytotoxic chemotherapy. J Cancer 2004; 90: 1306-11.

21. Huang L, Li J, Lau WY, et al. Perioperative reactivation of hepatitis $B$ virus replication in patients undergoing partial hepatectomy for hepatocellular carcinoma. J Gastroenterol Hepatol 2012; 27: 158-64.

22. Kubo S, Takemura S, Tanaka S, et al. Management of hepatitis $B$ virus infection during treatment for hepatitis B virus-related hepatocellular carcinoma. World J Gastroenterol 2015; 21: 8249-55.

23. Jun BG, Kim YD, Kim SG, et al. Hepatitis B virus reactivation after radiotherapy for hepatocellular carcinoma and efficacy of antiviral treatment: a multicenter study. PLoS One 2018; 13: e0201316.

24. Xu Z, Dai W, Wu YT, et al. Prophylactic effect of lamivudine on chemotherapy-induced hepatitis B virus reactivation in patients with solid tumour: a meta-analysis. Eur J Cancer Care (Engl) 2018; 27: e12799.
25. Yun J, Kim KH, Kang ES, et al. Prophylactic use of lamivudine for hepatitis B exacerbation in post-operative breast cancer patients receiving anthracycline-based adjuvant chemotherapy. Br J Cancer 2011; 104: 559-63.

26. Su YC, Lin PC, Yu HC, Wu CC. Antiviral prophylaxis during chemotherapy or immunosuppressive drug therapy to prevent HBV reactivation in patients with resolved HBV infection: a systematic review and meta-analysis. Eur J Clin Pharmacol 2018; 74: 1111-9.

27. Yeo W, Chan PK, Zhong S, et al. Frequency of hepatitis $B$ virus reactivation in cancer patients undergoing cytotoxic chemotherapy: a prospective study of 626 patients with identification of risk factors. J Med Virol 2000; 62: 299-307.

28. Huang H, Li X, Zhu J, et al. Entecavir vs lamivudine for prevention of hepatitis $B$ virus reactivation among patients with untreated diffuse large B-cell lymphoma receiving R-CHOP chemotherapy: a randomized clinical trial. JAMA 2014; 312: 2521-30.

29. Okita R, Takahashi M, Narahara $H$, et al. Use of entecavir to prevent hepatitis $\mathrm{B}$ virus reactivation during cytotoxic chemotherapy for solid malignancy. Clin J Gastroenterol 2009; 2: 214-7.

30. Remo M, Abraham I, Kankanala V, Chacra W, Danciu OC. Hepatitis $B$ reactivation in a patient receiving chemotherapy for breast cancer: a case report. Anticancer Res 2017; 37: 3791-3.

31. Zhang MY, Zhu GQ, Shi KQ, et al. Systematic review with network meta-analysis: comparative efficacy of oral nucleos(t)ide analogues for the prevention of chemotherapy-induced hepatitis B virus reactivation. Oncotarget 2016; 7: 30642-58.

32. Day FL, Karnon J, Rischin D. Cost-effectiveness of universal hepatitis $B$ virus screening in patients beginning chemotherapy for solid tumors. J Clin Oncol 2011; 29: 3270-7.

33. Kusumoto S, Tanaka Y, Mizokami M, Ueda R. Is antivira prophylaxis necessary to prevent hepatitis B virus (HBV) reactivation in patients with $\mathrm{HBV}$-resolved infection receiving rituximab-containing chemotherapy? J Clin Oncol 2013; 31: 4480.

34. Kumar R, Pérez-Del-Pulgar S, Testoni B, Lebosse F, Zoulim F. Clinical relevance of the study of hepatitis B virus covalently closed circular DNA. Liver Int 2016; 36 Suppl 1: 72-7. 